\title{
The Influence of Surface Roughness of Titanium on Bacterial Accumulation/Adhesion In Vitro
}

\author{
Georg Tellefsen ${ }^{1 *}$, Lars Linder ${ }^{1}$, Anders Liljeborg ${ }^{2}$ and Gunnar Johannsen ${ }^{1}$
}

${ }^{1}$ Department of Dental Medicine, Division of Periodontology, Karolinska Institute, Sweden

${ }^{2} \mathrm{KTH}$-Albanova, Nanostructurephysics, Sweden

\begin{abstract}
Bacterial biofilm formation on oral surfaces is a prerequisite for the development of diseases in the oral cavity, including perimplantitis. The aim of the present study was to evaluate the effect of titanium roughness and the composition of the growth medium on biofilm formation.

Single strain biofilm formation on titanium was studied in vitro with Streptococcus mutans IB. Commercially pure titanium specimens $(1.0 \times 1.0 \times 0.1 \mathrm{~cm})$ which are polished, sandblasted or untreated were used. Surface roughness was measured with a profilometer and expressed as a roughness value $\left(R_{a}\right)$. The titanium specimens were incubated in proteose-peptone medium containing either glucose or sucrose. Biofilm formation was initiated by inoculation with bacteria from a $17 \mathrm{~h}$ glucose-grown-culture. After 120 minutes bacteria were removed by washing and sonication from the titanium and the desorbed bacteria were quantified.
\end{abstract}

The biofilm obtained from the sucrose treated titanium contained $2.07 \times 10^{8} \pm 1.97 \times 10^{8}$ bacteria and $3.95 \times 10^{5} \pm$ $4.0 \times 10^{5}$ for the glucose treated titanium. No significant effect of the pretreatment of the titanium surface was observed. Sucrose, but not titanium surface roughness, played a significant role for $S$. mutans biofilm formation on titanium.

Keywords: Titanium; Bacterial adhesion; Biofilm formation

\section{Introduction}

Infections affecting dental implants, e.g. peri-implant mucositis and periimplantitis is a growing problem across the world. The prevalence at the individual level for peri-implant mucositis ranges from $48-80 \%$, and for periimplantitis $15-56 \%$ [1-4]. This represents a health-economic problem both on an individual level as well as for the society at large. The impact of surface properties of implant materials on bacterial adhesion and accumulation has been investigated by several authors [5-8]. The influence of tooth brushing with toothpaste on the surface roughness of teeth and dental materials has been shown by several authors $[9,10]$. The surfaces can also be influenced by different cleaning methods such as scaling and root planning. The properties of oral surfaces significantly affect the bacterial adhesion and biofilm formation. Bacteria that adhere to oral surfaces aggregate in a bacterial polymeric matrix to form biofilms.

Examples of biofilm induced infections are dental caries, periodontitis and periimplantitis. Roughness of different dental materials in relation to bacterial accumulation and growth were already in focus 20 years ago. Leonhardt et al. investigated titanium, hydroxyapatite and amalgam and found no significant differences between the materials regarding colonization of the bacteria investigated [11]. However, conflicting data have been presented. Busscher et al. claimed that more biofilm accumulated on rough than on smooth surfaces [12]. In contrast, Barbour et al. found that titanium polishing does not reduce oral bacterial colonization [13]. Likewise, Grössner-Schreiber et al. showed that no differences were seen between polished and laser treated titanium (which was rougher) in terms of bacterial colonies [14]. Increased demands on the esthetical appearance has resulted in the so called 'bone-level' implants, meaning that the prosthetic part of the replacement are in many cases placed $4-5 \mathrm{~mm}$ subgingivally, which may implicate a risk for plaque accumulation and thus a risk for periimplant mucositis. It has also been suggested that lesions produced in experimental periodontitis, and periimplantitis are different and that implant surface characteristics influence the inflammatory process in experimental peri-implantitis and the magnitude of the resulting tissue destruction [15]. It is therefore of great importance to further exploring the importance of surface roughness on bacterial accumulation.

The aim of the present investigation was to investigate the influence of surface roughness on bacterial accumulation in vitro on titanium.

\section{Materials and Methods}

\section{Titanium specimens and surface treatment}

6 flat square machined titanium specimens with the dimensions $10 \times 10 \mathrm{~mm}$ and a thickness varying from 1.1 to $1.3 \mathrm{~mm}$, was obtained from an implant company (Nobel BioCare ${ }^{\bullet}$ ). To simulate the wear of tooth brushing with toothpastes, the specimens were subjected to brushing with toothbrushes and toothpastes in a brushing machine for 12000 double strokes. Since no changes in the surface roughness of the Titanium specimens could be detected, the following procedure was performed to simulate the wear from scaling and root planing.

Two specimens were polished using sanding sheets: SIA ${ }^{\circledR} 1951$ siawat P280, 3M $\mathrm{M}^{\oplus}$ Wetordry Tri-M-ite P400, P600, and P1200 used in this order. Subsequently, we applied $3 \mathrm{M}$ Imperial Lapping Film grades 12, 3, and 0.3 microns. Finally, Polierpasten-Riegel, PP4 HGP from $\mathrm{Pferd}^{\circledR}$ was used to obtain a mirror or glossy appearance (Figure 1). Two specimens retained their original (turned) roughness (Figure 2) and two specimens were sandblasted with $250 \mu \mathrm{m}$ aluminum oxide particles from Simed for 7 minutes on each side (Figure 3). All

*Corresponding author: Dr. Georg Tellefsen, Department of Dental Medicine Division of Periodontology, Karolinska Institute, Box 4064, 14104 Huddinge, Sweden, Tel: +46 87536140; E-mail: georg.tellefsen@ptj.se/ georg.tellefsen@telia.com

Received December 19, 2015; Accepted January 27, 2016; Published February 03, 2016

Citation: Tellefsen G, Linder L, Liljeborg A, Johannsen G (2016) The Influence of Surface Roughness of Titanium on Bacterial Accumulation/Adhesion In Vitro. Dentistry 6: 361. doi:10.4172/2161-1122.1000361

Copyright: (c 2016 Tellefsen G, et al. This is an open-access article distributed under the terms of the Creative Commons Attribution License, which permits unrestricted use, distribution, and reproduction in any medium, provided the original author and source are credited. 

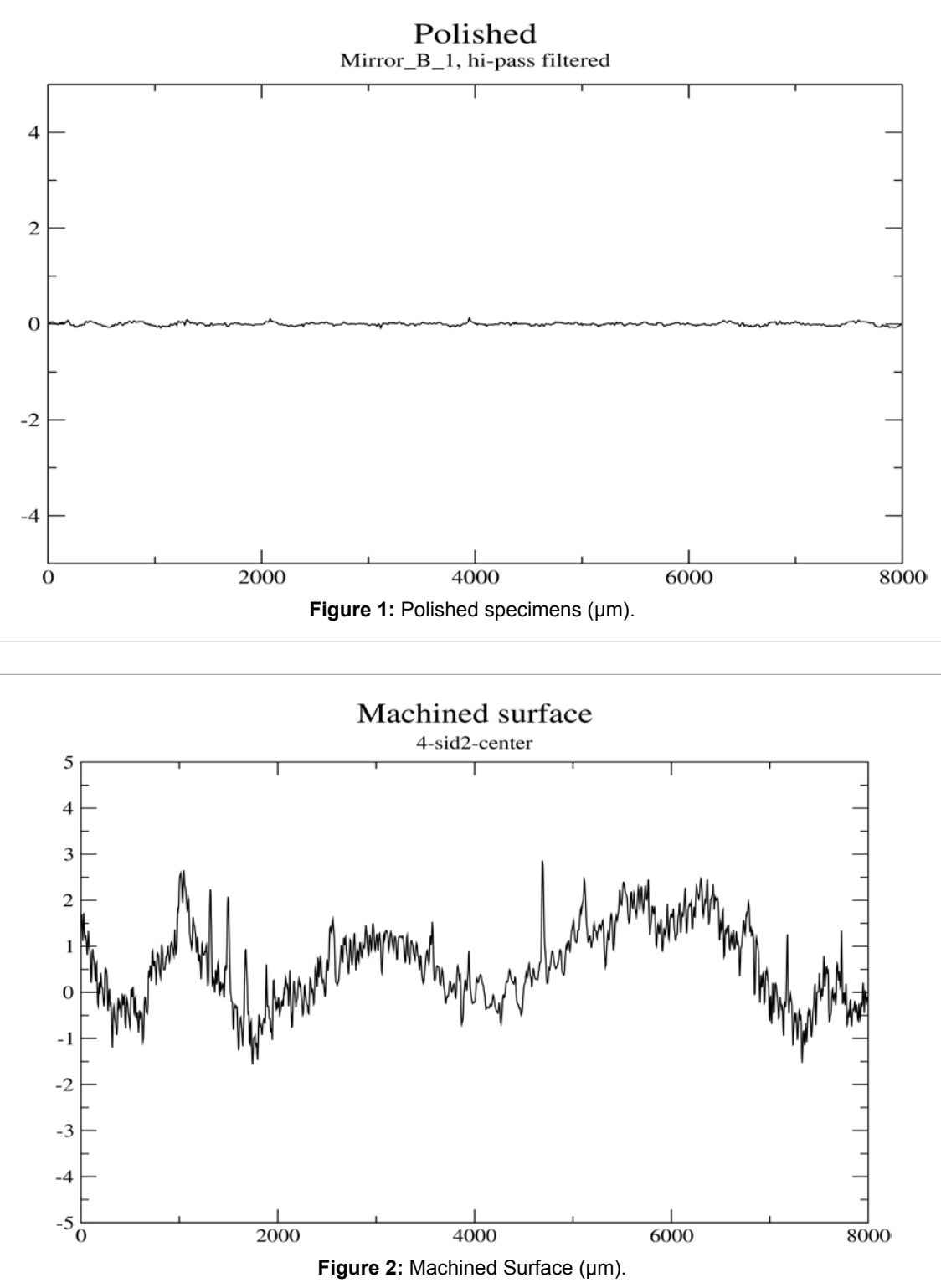

6 specimens were treated in the same way on both sides. They were washed, using an ultrasonic bath for 20 minutes in distilled water and then in $96 \%$ ethanol.

The roughness was evaluated in a Profilometer, measuring the $\mathrm{R}_{\mathrm{a}}$ value. $R_{a}$ is defined as the arithmetic average deviation of the absolute values of the roughness profile from the mean line or the center line. This instrument has been used in previous studies, and has an ability to detect structure unevenness on a surface of about $50 \mathrm{~nm}[16,17]$. The ultimate lateral resolution is $25 \mathrm{~nm}$ in $\mathrm{x}$-direction and $1 \mu \mathrm{m}$ in $y$-direction. However, the actual resolution is a function of stylus radius. The scan repeatability is $7.5 \AA$ (Angstrom) or $0.1 \%$ of step height, and the reproducibility is $15 \AA$ or $0.25 \%$ of step height (as specified by the manufacturer). The results from the $\mathrm{R}_{\mathrm{a}}$ measurements are listed in Table 1.

\section{Bacterial strain and growth conditions}

Streptococcus mutans Ing Britt (IB), a serotype c strain was obtained from lyophilized ampoules and precultures were grown for $16 \mathrm{~h}$ at $37^{\circ} \mathrm{C}$ in Brain-Heart Infusion Broth with $1 \%$ glucose $(\mathrm{BHI})$. In order to obtain late exponential phase cells, a $1 \mathrm{ml}$ portion of the preculture was used to inoculate $100 \mathrm{ml}$ BHI medium containing $1 \%$ of either glucose or sucrose as energy source and grown for $8-10 \mathrm{~h}$ at $37^{\circ} \mathrm{C}$. The bacteria were sedimented by centrifugation $(10,000 \mathrm{~g}, 10 \mathrm{~min}$ at room temperature) and washed three times in cold $0.02 \mathrm{M}$ phosphate buffered saline (PBS) with $\mathrm{pH} 7.2$ and then homogenized with a glass tissue grinder equipped with a teflon plunge (A.H. Thomas, USA) and used without delay in the adhesion or biofilm assays. BHI medium is composed of Brain Heart Infusion Broth (BHI) (Difco ${ }^{\mathrm{Tx}}$ ) $4.0 \mathrm{~g}$, FMC medium $0.5 \mathrm{~g}$, cysteine $0.1 \mathrm{~g}$, dipotassium phosphate $\left(\mathrm{K}_{2} \mathrm{HPO}_{4}\right) 0.2 \mathrm{~g}$, monosodium phosphate $\left(\mathrm{NaH}_{2} \mathrm{PO}_{4}\right) 0.04 \mathrm{~g}$ and glucose $1.0 \mathrm{~g}$ distilled to a final volume of $100 \mathrm{ml}$. This procedure was then repeated with addition of sucrose instead of glucose.

\section{Adhesion assays}

Washed bacteria were transferred to $0.02 \mathrm{M}$ PBS $\mathrm{pH}$ 7.2. The three types of titanium specimens as described previously were immersed 


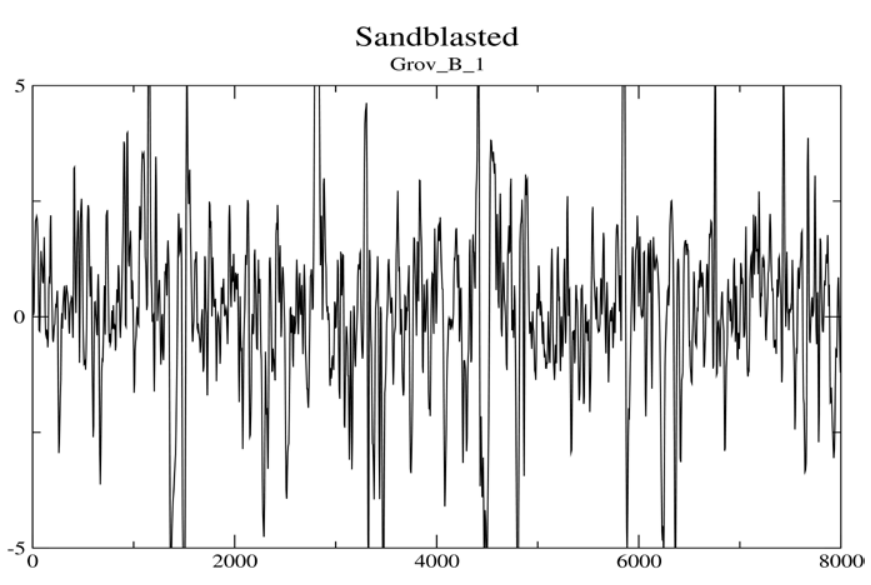

Figure 3: Sandblasted specimens $(\mu \mathrm{m})$.

\begin{tabular}{|c|c|c|}
\hline Titanium specimen & Plate I, $\mathbf{R}_{\mathbf{a}}(\mu \mathrm{m})$ & Plate II, $\mathbf{R}_{\mathbf{a}}(\mu \mathrm{m})$ \\
\hline Polished & 0.026 & 0.029 \\
\hline Machined surface (original) & 0.489 & 0.254 \\
\hline Sandblasted & 2.12 & 1.67 \\
\hline
\end{tabular}

Table 1: Mean values of the $\mathrm{R}_{\mathrm{a}}$ measurements.

separately into $2.0 \mathrm{ml}$ freshly prepared cell suspensions in glass tubes and incubated at room temperature for $2 \mathrm{~h}$. To quantify the bacterial adhesion on each sample type, the titanium specimens were then washed three times in $10 \mathrm{mM}$ PBS pH 7.2 and subsequently transferred to $2.0 \mathrm{ml} 0.02 \mathrm{M}$ PBS $\mathrm{pH} 7.2$ and sonicated for $5 \mathrm{~min}$ at room temperature (Elmasonic S, Elma GmbH \& Co KG, Singen, Germany) and then vortexed for $15 \mathrm{sec}$ to release adsorbed bacteria. The released bacteria were serially diluted and incubated on Mitis Salivarius Agar and cultivated anaerobically in a GasPak for $48 \mathrm{~h}$. We assume a baseline of zero cells. Cell growth from bath respective to sample type and any growth demonstrated from the biofilm variables will be growth from the biofilm condition itself. The number of bacteria was determined as the mean value of three dilutions.

In order to study the role of glucosyltransferases and glucan formation on primary adhesion of $S$. mutans IB to titanium specimens these were preincubated for $2 \mathrm{~h}$ at $37^{\circ} \mathrm{C}$ with a combination of $2 \%$ sucrose and culture supernatants from glucose-grown cultures of S. mutans IB containing released glucosyltranferases. Titanium specimens preincubated without sucrose were used as controls. The titanium specimens were then washed three times in cold a.d. and then incubated with washed glucose-grown exponential-phase cells for $2 \mathrm{~h}$ at room temperature. The cells were desorbed and quantified by the standard procedures.

In order to investigate the effect of experimental saliva pellicle on cell adhesion in some experiments the titanium specimens were preincubated with clarified saliva for one hour. Stimulated saliva was obtained from two of the authors and clarified by centrifugation $(10,000 \mathrm{~g}$ for $10 \mathrm{~min})$. In some experiments the number of residual bacteria on the titanium specimens after desorption were estimated by a semiquantitative method. The specimens were washed once in a.d. and then pressed against the surface of an MSB-agar plate. After anaerobic incubation at $37^{\circ} \mathrm{C}$ for $48 \mathrm{~h}$ the number of colonies was counted.

\section{Biofilm assays}

The three types of titanium specimens were incubated in duplicates with washed cells in $2.0 \mathrm{ml} \mathrm{BHI}$ with either sucrose or glucose for 4 hours at $37^{\circ} \mathrm{C}$. Desorption of bacteria and viable count was conducted as described above.

\section{Results}

The $R_{a}$ values of the titanium specimens are shown in Table 1 , where obvious differences in surfaces roughness can be observed. The roughest surface was shown by the sandblasted specimen and the smoothest by the polished specimen. Statistical analyses revealed that no difference regarding bacterial accumulation in relation to titanium roughness could be detected. Primary bacterial adhesion was significantly stimulated by previous growth in medium containing sucrose compared to growth in glucose medium was $1.1 \times 10^{7} \pm$ $0.7 \times 10^{7}$ and $9.5 \times 10^{4} \pm 0.97 \times 10^{4}$ respectively $(\mathrm{p}<0.05)$. Biofilm formation conducted in growth medium containing sucrose contained significantly more bacteria $\left(2.07 \times 10^{8} \pm 1.97 \times 10^{8}\right)$ than in the presence of glucose $\left(3.95 \times 10^{5} \pm 4.010^{5}\right)(\mathrm{p}<0.05)$. The mean values were calculated out of six experiments.

Primary adhesion to titanium preincubated with glucosyltranferases and sucrose showed higher amounts of bacteria compared to the control. The tendency was strong although not statistically significant $(p<0.058)$. Salivary pellicle did not seem to affect primary adhesion or biofilm formation. The experiments conducted to determine residual bacteria after the desorption process revealed that $0.5-1 \%$ of the amount of desorbed bacteria remained on the specimens.

\section{Discussion}

The first experiment revealed that the influence of tooth brushing with toothpastes or polishing with commonly used clinically polishing pastes or even with pumice slurries had no effect on the titanium in terms of altering the roughness of the specimens. Contradictory to these, Hossain et al. showed that the surface of titanium could be altered by using toothpastes [10]. However they used a brushing machine and brushed altogether 350,000 strokes. To extrapolate these in vitro results into a clinical reality this would correspond to approximately 20 years of tooth brushing twice daily [18]. In order to be able to analyze the effect of surface roughness on bacterial accumulation, in the present study different degrees of roughness on the titanium specimens were created by the method presented in the materials and methods part. However, neither primary adhesion nor biofilm formation by $S$. mutans IB was influenced by titanium surface roughness. This is in line with a study by Leonhardt et al. who investigated bacterial growth on among other materials also titanium. They found no significant differences between the materials regardless of surface roughness [11].

Mabboux et al. showed, somewhat contradictory results, that two different strains of Streptococcus with hydrophobic and hydrophilic properties adhered differently depending on the surface energy (SFE) of titanium with different coating [19]. They stated that physico-chemical surface properties of oral bacterial strains play a role in bacterial retention to implant materials in the presence of adsorbed salivary proteins. On the other hand Bürgers et al. found that bacterial adhesion on titanium was affected by surface roughness, while the influence of surface free energy (SFE) seemed to be of minor importance, and the conclusion was that a highly polished surface is best to prevent plaque accumulation [8]. In the present study $S$. mutans IB was used as this bacterium plays an important role in biofilm formation, and also that it in earlier studies has shown to adhere well to solid surfaces $[11,20]$. In other in vitro studies different bacteria have been used. Fröjd et al. compared biofilm formation by $S$. sanguinis and Actinomyces naeslundii on three different surfaces and found no differences [21]. 
Regarding the influence of saliva, the present study did not show any additional effect on bacterial adhesion, which is an important finding since salivary glycoproteins are essential for the initial pellicle formation. This is in line with the results found by Lima et al. who stated that pre-coating of titanium surfaces with experimental salivary pellicle, did not affect the adherence of $A$. naeslundi [22]. However, in that study, the bacteria were suspended in nutrient broth and not in saliva. Fröjd et al. on the other hand found a significantly greater biofilm volume, when saliva was added on three different titanium surfaces [20]. The contradictory results could be due to the different bacteria used, namely $S$. sanguinis and A. naeslundi.

The significance of the dilutions was also investigated in the present study, where dilution of $10^{5}$ did not show any growth; adhesion or biofilm formation, while dilution of $10^{9}$ showed a degree of both adhesion and biofilm formation on the titanium specimens. In our experiments the initial cell concentration was found important both in primary adhesion and in biofilm formation. At initial cell concentrations less than $10^{7}$, the amount of adhering bacteria was relatively low. Furthermore the amount of adhering bacteria was not proportional to the initial cell concentration. We therefore used initial cell concentrations of about $10^{9}$.

In vitro studies on the adherence of $S$. mutans to various solid surfaces have shown the dependence on active synthesis of waterinsoluble glucan [19]. Sucrose dependent firm adhesion of S. mutans to glass has shown to require simultaneous de novo synthesis of water insoluble glucan by glycosyltranferases [23]. This is to a certain extent supported in our study where the presence of sucrose yielded more bacterial growth than when only glucose was added. Limitations of this study are the small number of specimens and that it is an in vitro study. To be able to extrapolate these results into a clinical reality it is therefore important to repeat this study in vivo.

\section{Conclusions}

Given the small number of specimens, the present study yielded the following conclusions. The surface roughness of the titanium plates had no influence on bacterial accumulation. Furthermore, the bacterial growth was more pronounced in the biofilm experiment than in the primary adhesion experiment. The presence of sucrose in growth media significantly increased adhesion and accumulation on titanium compared to glucose.

\section{Acknowledgments}

This study was supported by Praktikertjänst AB, Stockholm, Sweden.

\section{References}

1. Roos-Jansåker AM, Lindahl C, Renvert H, Renvert S (2006) Nine- to fourteenyear follow-up of implant treatment. Part II: implant loss and associations to various factors. J Clin Periodontol 33: 290-295.

2. Lindhe J, Meyle J (2008) Peri-implant diseases: Consensus Report of the Sixth European Workshop on Periodontology. J Clin Periodontol 35: 282-285.

3. Zitzmann NU, Berglundh T (2008) Definition and prevalence of peri-implant diseases. J Clin Periodontol 35: 286-291.

4. Atieh MA, Alsabeeha NH, Faggion CM Jr, Duncan WJ (2013) The frequency of peri-implant diseases: a systematic review and meta-analysis. J Periodontol 84: $1586-1598$.
5. Quirynen M, van der Mei HC, Bollen CM, Schotte A, Marechal M, et al. (1993) An in vivo study of the influence of the surface roughness of implants on the microbiology of supra- and subgingival plaque. J Dent Res 72: 1304-1309.

6. Quirynen M, Bollen CM, Papaioannou W, Van Eldere J, van Steenberghe D (1996) The influence of titanium abutment surface roughness on plaque accumulation and gingivitis: short-term observations. Int J Oral Maxillofac Implants 11: 169-178.

7. Bollen CM, Papaioanno W, Van Eldere J, Schepers E, Quirynen M, et al (1996) The influence of abutment surface roughness on plaque accumulation and peri-implant mucositis. Clin Oral Implants Res 7: 201-211.

8. Bürgers R, Gerlach T, Hahnel S, Schwarz F, Handel G, et al. (2010) In vivo and in vitro biofilm formation on two different titanium surfaces. Clin Oral Implants Res 21: 156-164.

9. Johannsen G, Redmalm G, Rydén H (1992) Surface changes on dental materials. II. The influence of two different dentifrices on surface roughness measured by laser reflexion and profilometer techniques. Swed Dent J 16: 1320.

10. Hossain A, Okawa S, Miyakawa O (2006) Effect of toothbrushing in titanium surface: an approach to understanding surface properties of brushed titanium. Dent Mater 22: 346-352.

11. Leonhardt A, Olsson J, Dahlén G (1995) Bacterial colonization on titanium hydroxyapatite, and amalgam surfaces in vivo. J Dent Res 74: 1607-1612.

12. Busscher HJ, Rinastiti M, Siswomihardjo W, van der Mei HC (2010) Biofilm formation on dental restorative and implant materials. J Dent Res 89: 657-665.

13. Barbour ME, O'Sullivan DJ, Jenkinson HF, Jagger DC (2007) The effects of polishing methods on surface morphology, roughness and bacterial colonisation of titanium abutments. J Mater Sci Mater Med 18: 1439-1447.

14. Grössner-Schreiber B, Griepentrog M, Haustein I, Müller WD, Lange KP, et al. (201) Plaque formation on surface modified dental implants. An in vitro study. Clin Oral Implants Res 12: 543-551.

15. Carcuac O, Abrahamsson I, Albouy JP, Linder E, Larsson L, et al. (2013) Experimental periodontitis and peri-implantitis in dogs. Clin Oral Implants Res 24: 363-371.

16. Liljeborg A, Tellefsen G, Johannsen G (2010) The use of a profilometer for both quantitative and qualitative measurements of toothpaste abrasivity. Int J Dent Hygiene 8: 237-243.

17. Tellefsen G, Liljeborg A, Johannsen A, Johannsen G (2011) The role of the toothbrush in the abrasion process. Int J Dent Hyg 9: 284-290.

18. Van Dijken JWV, Ruyter El (1987) Surface characteristics of posterior composites after polishing and toothbrushing. Acta Odontol Scand 45: 337 346 .

19. Mabboux F, Ponsonnet L, Morrier JJ, Jaffrezic N, Barsotti O (2004) Surface free energy and bacterial retention to saliva-coated dental implant materials-an in vitro study. Colloids Surf B Biointerfaces 39: 199-205.

20. Hamada S, Slade HD (1980) Biology, immunology, and cariogenicity of Streptococcus mutans. Microbiol Rev 44: 331-384.

21. Fröjd V, Linderbäck $P$, Wennerberg $A$, Chávez de Paz L, Svensäter G, et al (2011) Effect of nanoporous TiO2 coating and anodized Ca2+ modification of titanium surfaces on early microbial biofilm formation. BMC Oral Health 11: 8.

22. Lima EM, Koo H, Vacca Smith AM, Rosalen PL, Del Bel Cury AA (2008) Adsorption of salivary and serum proteins, and bacterial adherence on titanium and zirconia ceramic surfaces. Clin Oral Implants Res 19: 780-785.

23. Koga T, Asakawa H, Okahashi N, Hamada S (1986) Sucrose-dependent cell adherence and cariogenicity of serotype c Streptococcus mutans. J Gen Microbiol 132: 2873-2883. 